\title{
When your face doesn't fit: Employment discrimination against people with facial disfigurement.
}

Corresponding Author:

Dr Anna Stone

School of Psychology

University of East London

Water Lane

Stratford

London E15 4LZ

United Kingdom

Email: a.stone@uel.ac.uk

Second author:

Mr Toby Wright

Address as above 


\begin{abstract}
This study aimed to investigate the recruitment prospects of people with facial disfigurement and a contrasting group of wheelchair users, representing a functional impairment with little aesthetic impact. Three applications were made to each of 144 vacancies using three CVs and cover letters rotated around conditions in which one applicant was described as a wheelchair user, another had a non-contagious facial disfigurement, and the third (control condition) had neither. There was evidence of discrimination against people with facial disfigurement in jobs requiring high (but not low) levels of customer contact, and against wheelchair users for jobs entailing high or low customer contact. Aesthetic considerations, social norms, and the possibility of stigma by association are discussed as potential underlying factors.
\end{abstract}

Key words: recruitment study, discrimination, disability, facial disfigurement 
When your face doesn't fit

\section{Introduction}

It is well documented that a number of different groups are affected by discrimination in the recruitment process. Women, ethnic and national minorities, disabled workers, older workers, homosexuals, and people with criminal records, have been observed to face unfavourable hiring decisions (e.g. Firth, 1981; 1982; Jowell \& Prescott-Clarke, 1970; Newman, 1978; Pager \& Quillian, 2005; Riach \& Rich, 1991; 2004; 2007; Tartaglia, McMahon, West \& Belongia, 2005; Weichselbaumer, 2003). The present study was designed to investigate whether people with facial disfigurement would suffer from recruitment discrimination in several frequently-advertised types of employment and to explore underlying factors. Discrimination was defined as a reduced likelihood of being offered an interview following submission of an application to an advertised vacancy when information in the application revealed that the applicant had a facial disfigurement. There appears to be a gap in the literature with no actual recruitment study having been reported, to our knowledge, examining the issue of facial disfigurement or the underlying psychological mechanisms of recruitment discrimination.

The present study employed the frequently-used method of Correspondence Testing (e.g. Riach \& Rich, 2002) which typically entails the sending of two or more similar applications to employers in which the applications are alternated and allocated equally often to the different conditions of the study. This controls for any unintended difference between application materials so that any observed difference in outcomes can be attributed to the experimental 
conditions. To help explore the factors underlying any observed recruitment discrimination the effect of a facial disfigurement was compared with the impact of mobility impairment and with an unimpaired control condition. A facial disfigurement imposes a purely cosmetic impairment with no functional impact, and so the wheelchair-user condition was included for contrast as a functional impairment with minimal cosmetic impact (and not affecting the face) in order to gain some insight into underlying mechanisms of discrimination. The choice of experimental conditions permits the exploration of the relative impact of aesthetic considerations and practical necessities on the employment prospects of people with facial disfigurement or impaired mobility.

The literature on employment discrimination against people with physical disability suggests that there is a substantial degree of discrimination against wheelchair-users in recruitment (e.g. Fry, 1986; Graham, Jordan \&Lamb, 1990). There appears to be no direct empirical evidence of recruitment discrimination against people with facial disfigurement, but indirectly, there is evidence that employers tend to favour attractive applicants over less attractive applicants (e.g. Cash \& Kilcullen, 1985; Gilmore, Beehr \& Love, 1986; Marlowe, Schneider \& Nelson, 1996; Miller \& Routh, 1985). There are also many anecdotal accounts of discrimination observed by people with facial disfigurements (e.g. Clarke, 1999; Hearst \& Middleton, 1997; Lanigan \& Cotterill, 1989; Rumsey \& Harcourt, 2004; Walters, 1997).

In contrast, studies in simulated employment settings have often reported favourable treatment of fictional job applicants with disability. There have been 
several reports of positive bias towards a fictional job applicant with impaired mobility from undergraduate students (Gouvier, Sytsma-Jordan \& Mayville, 2003) or employees (Bell \& Klein, 2001; Christman \& Slaten, 1991; Nordstrom, Huffaker \& Williams, 1998; but see also Colella, DeNisi \& Varma, 1998). Turning to facial disfigurement, Stevenage and McKay (1999) reported a study in which recruitment consultants stated a $100 \%$ likelihood of employing an applicant with a facial disfigurement (port wine stain) for a general administrative position. As was noted by the authors, this was inevitable given the consultants' knowledge of legislation and awareness that their responses would be observed. Finally, there are reports in which UK employers claim to have responded favourably to the provisions of the Disability Discrimination Act 2004 (e.g. Jackson, Furnham \& Willen, 2000; Bruyere, Erickson \& VanLooy, 2004). It appears that in a simulated setting, where hiring decisions have no actual consequence, the "norm to be kind" or motives of social sympathy may prevail so that positive discrimination is observed (e.g. Bell \& Klein, 2001; Loo, 2001; Colella et al, 1998).

Regarding the employment of people with disability or disfigurement it seems the relationship between attitude and behaviour may be weak (e.g. Devine, 1989; Pryor, Reeder, Yeadon \& Hesson-McInnis, 2004). A similar conclusion was reached by Wilgosh and Skaret (1987) in a literature review which revealed that attitudes towards the hiring of people with disabilities obtained in experimental settings were more positive than the actual hiring practice. Without the obligation to follow through a stated willingness to employ a fictitious applicant, a participant in a mock recruitment study may not explore all 
of their complex reactions to an applicant with unusual characteristics (e.g. Wilgosh \& Skaret, 1987). In a real-world situation where there are actual consequences of a decision to employ it is more likely that negative reactions would be observed (e.g. Louvet, 2007; Wilgosh \& Skaret, 1987).

This suggests that mock recruitment studies, or other types of employer self-report measure, should not be relied upon as the sole predictors of actual behaviour. It seems advisable to also employ unobtrusive methods in real-world settings in order to gain a fuller picture of the employment prospects of people with disfigurements or disabilities, and to begin the exploration of potential underlying factors.

Turning to the factors potentially underlying recruitment discrimination, one important potential source of discrimination is a stereotyping process by which the mere presence of a facial disfigurement or mobility impairment might cause the perceiver to generate lower impressions of the social and occupational competencies of the applicant (e.g. Heilman, 1983). Several studies have examined how people with disabilities are evaluated in general settings, and a number of consistent factors have emerged (e.g. Bell \& Klein, 2001; Fichten \& Amsel, 1986; Kelly, Sedlacek \& Scales, 1994; Loo, 2001; Louvet, 2007; Stone \& Colella, 1996). People with disabilities are evaluated as being more quiet, shy, unsociable, and lower in interpersonal competence. They are also perceived as being less well emotionally adjusted (more anxious, depressed, and unstable) and more dependent on others. In addition, they are generally evaluated as lower in task competence and various skills commonly desired by employers. On the 
When your face doesn't fit

positive side, people with disabilities are seen as being kinder towards others and more honest, open and conscientious, or more agreeable. The literature on facial disfigurement has tended to report similar views, for example, Bull and David (1986) found that people with a small scar on their face were perceived as less sociable and confident than people without a visible scar. Stevenage and McKay (1999) reported lower evaluations of a person with a port-wine stain than a nondisfigured control over a range of items including several tapping into social confidence and skills, and work-relevant competencies.

A second important factor is the dimension of aesthetics which refers to the perception of the individual as ugly, repulsive, or upsetting (e.g. Stone \& Colella, 1996). The more unattractive the disability or disfigurement, the more negative will be others' reactions. It seems likely that the job applicants with facial disfigurement would have been more disadvantaged in this respect than the applicants who were wheelchair users. The face is the focus of social interaction and an important source of social information and hence a facial disfigurement would be particularly obtrusive, as well as being hard to conceal. Although a wheelchair is generally a negative stimulus and is also very visibly noticeable, it lacks the negative aesthetic impact of a facial disfigurement.

There is empirical evidence suggesting that people with facial disfigurements might invoke a particularly strong negative implicit attitude. For example, Giancoli and Neimeyer (1983) asked 100 students to rank 6 drawings of people in order of which they liked best: people depicted as non-disabled or as wheelchair users were well liked, while people depicted as facially disfigured 
When your face doesn't fit

were particularly poorly liked. There is also evidence that some members of the general public may avoid physical proximity to a person with a facial disfigurement. For example, people have maintained a greater distance from an experimental confederate with a mock facial disfigurement when waiting to cross a road (Rumsey, Bull \& Gahagan, 1982) or when choosing a seat in a railway carriage (Houston \& Bull, 1994). Physiological responses revealed that participants experienced more stress in interacting with an experimental confederate with a simulated birthmark than without such disfigurement (Blascovich, Mendes, Hunter, Lickel, \& Kowai-Bell, 2001).

Of particular interest is the observation by Eagly, Ashmore, Makhijani, and Longo (1991) that people with conditions of disability or disfigurement that are considered unattractive are less likely to be given tasks requiring customer contact. Also, a study of successful employment tribunal actions for discrimination brought against employers (Tartaglia et al, 2005) reported that discrimination against people with disfigurement was particularly high in the retail and service industries, in which there are typically high levels of customer contact, and lower in construction and manufacturing, with lower levels of customer contact. It is generally considered good practice to evaluate an application against the essential requirements of the job rather than against an abstract notion of the 'ideal candidate' (e.g. Stone \& Colella, 1996). However, according to Dembo, Leviton and Wright (1975), people may be implicitly judged against a standard or norm that represents the abstract conception of the requirements of a role. The implicit concept of the 'ideal candidate' is unlikely to 
When your face doesn't fit

include a facial disfigurement and so appearance considerations may influence recruitment decisions.

The implication for the present study is that recruitment discrimination against people with facial disfigurement would be particularly severe in jobs with a high level of customer contact. It is relevant to note that the prospective employer would be reading the application not only in accordance with their own attitudes and values but also in accordance with the assumed attitudes and values of those people with whom the successful applicant would interact professionally. It seems plausible to suppose that a potential employer or recruitment consultant would seek to avoid any future problems by taking a cautious approach, and this could dictate avoidance of an applicant of unusual appearance. As Smith and Collins (2009) pointed out, person perception does not take place in a vacuum, but against a backdrop of wider cultural perceptions. The perceptual processes of the reviewer interact with this 'environment of belief' to produce the perceptual outcome. Thus, if the perceiver believes that a person of unusual appearance would tend to attract some unfavourable responses that might be a sufficient reason to reject their application.

To examine the influence of aesthetics on recruitment decisions the jobs to which applications were made had different levels of expected customer contact. Jobs with low levels of customer contact were IT Support Analyst and Personal Assistant, while jobs with higher customer contact were Administrator/ Receptionist and Graduate Sales. Aesthetics predicts that discrimination should be strongest where the demand for customer contact is greatest, and this effect 
should be more apparent for the applicants with facial disfigurement than for the wheelchair users.

Another consideration is that if the potential costs of practical accommodations are a major concern for employers then this would impact more severely on the recruitment prospects of people with mobility impairment than those with facial disfigurement, across all job types.

The present study was designed to investigate recruitment discrimination in jobs in which there was no valid justification. Therefore, jobs were selected for which facial appearance and mobility are both irrelevant considerations, and the application materials were constructed to present a strong application with good qualifications and communication skills, so that any observed discrimination would depend on attitudes of the employer.

\section{Method}

Participants. The sample consisted of 144 companies based in London who were actively recruiting for one of four types of job vacancies: office administrator / receptionist (AR), personal assistant (PA), information technology support analyst (IT) or graduate salesperson (GS; this is simply a salesperson who holds a university degree). There were 36 companies for each type of position.

The four job types were selected following a survey conducted by the authors of around 60 employers in London with current advertised vacancies, to enquire how many applications they expected to receive. Responses suggested 
that a vacancy in any of the 4 selected job types would typically be expected to attract more than 40 applications, so that the additional 'fake' applications would not stand out. A small sample of the companies (6 for each job type) was contacted by telephone to enquire as to the number of applications the position had received. All of the companies contacted for this purpose reported receiving a high response to the adverts, with numbers of genuine applications ranging from 25 to 250 .

Companies were selected by obtaining advertisements for the relevant positions sourced on recruitment websites and in the local media. A company was suitable for inclusion in the study if the application process required only a CV and a covering letter, so that standard pre-prepared materials could be used in order to maintain a high level of experimental control. Of the 144 companies, 59 (41\%) were recruiting directly and 85 (59\%) were using a recruitment agency. The current recruitment market is such that it is nearly impossible to eliminate the involvement of recruitment agencies when applying for certain job types and therefore it was decided that applications through recruitment agencies would be included.

The companies recruiting directly fell into the following sectors: Goods and services (18.1\%), Communications and media (9.7\%), Legal and financial (6.9\%) and Architecture and design (6.3\%). The size of the company was determined for 53 companies and ranged between two and two thousand with a mean company size of 153 persons. 
Materials. Three CVs with cover letters were constructed for each of the job types, $12 \mathrm{CVs}$ and cover letters altogether, so that each was specifically designed to appeal to one of the four job types. These were based on the examination of a set of genuine, anonymous CVs and cover letters obtained from professional recruitment consultants for each type of job. Care was taken to ensure that the finished $\mathrm{CVs}$ bore no resemblance to the initial genuine CVs. Each of the three CVs in a job type were designed to be equivalent in terms of human capital but to differ substantially in design and layout in order to prevent experiment transparency. Once completed, all CVs were submitted to 7 independent recruitment industry professionals currently working for recruitment consultancies and recruitment agencies in London, UK. These people confirmed that the CVs were all realistic and of appropriate quality for the corresponding type of job, and confirmed that the three CVs for each job represented three individuals of equivalent potential. The formal qualifications, and experience in similar positions, of the 3 individuals applying for each type of job are shown in Table 1. 
Table 1: Formal qualifications and previous experience in similar positions of the job applicants.

\begin{tabular}{|c|c|c|c|}
\hline Job Type & Individual & Qualifications & $\begin{array}{l}\text { Experience in } \\
\text { similar positions }\end{array}$ \\
\hline $\begin{array}{l}\text { IT support } \\
\text { analyst }\end{array}$ & $\begin{array}{l}1 \\
2\end{array}$ & $\begin{array}{l}\text { Microsoft Certified Professional } \\
\text { and Certified Technician } \\
\text { Microsoft Certified Professional } \\
\text { and BSc Computer Networking } \\
\text { (third class) } \\
\text { Microsoft Certified Professional } \\
\text { and NVQ level III }\end{array}$ & $\begin{array}{l}5 \text { years } \\
6 \text { years } \\
5 \text { years }\end{array}$ \\
\hline $\begin{array}{l}\text { Personal } \\
\text { assistant }\end{array}$ & $\begin{array}{l}1 \\
2 \\
3\end{array}$ & $\begin{array}{l}4 \text { A-levels } \\
3 \text { A-levels \& } 1 \text { NVQ level III } \\
3 \text { A-levels }\end{array}$ & $\begin{array}{l}9 \text { years } \\
10 \text { years } \\
10 \text { years }\end{array}$ \\
\hline $\begin{array}{l}\text { Administrator } \\
\text { / receptionist }\end{array}$ & $\begin{array}{l}1 \\
2 \\
3\end{array}$ & $\begin{array}{l}\text { University degree (lower second) } \\
\text { University degree (upper second) } \\
\text { University degree (upper second) }\end{array}$ & $\begin{array}{l}7 \text { years } \\
6 \text { years } \\
7 \text { years }\end{array}$ \\
\hline $\begin{array}{l}\text { Graduate } \\
\text { Sales }\end{array}$ & $\begin{array}{l}1 \\
2 \\
3\end{array}$ & $\begin{array}{l}\text { University degree (upper second) } \\
\text { University degree (upper second) } \\
\text { University degree (upper second) }\end{array}$ & $\begin{array}{l}5 \text { years } \\
6 \text { years } \\
5 \text { years }\end{array}$ \\
\hline
\end{tabular}

Table 1 note: an A-level is a school-leaving examination taken at the age of 18 or 19, or it can be taken by an adult at any age. An NVQ level III is equivalent to an A-level. 
The level of expected customer contact varies among these job types, being highest for the graduate sales, then the administrator-receptionist positions, followed by the personal assistants, and lowest for the IT support analyst role. This ranking was verified by consulting the "O-NET" website in the USA which lists the work activities involved in different jobs. The work activities selected as particularly involving customer contact were "communicating with persons outside the organisation", "selling or influencing others", and "working directly with the public". The mean requirement for the relevant work activities (on a scale from 1 to 100) were as follows: IT Support = 39 (Computer Support Specialist), PA = 56 (Executive Secretary), Admin-receptionist $=60$ (Receptionist and Information Clerk), and Graduate Sales = 67 (Sales Representatives).

The CVs constructed for the present study all showed that the applicant was currently employed in a similar position and was seeking a new position to further their career and was under 30 years old. This was designed to make the applicants seem attractive as prospective employees following evidence that younger applicants and those who are gainfully employed are considered by rehabilitation professionals to be easier to place in work (e.g. Tsang, Chan \& Chan, 2004; Wong, Chan, De Silva Cardoso, Lam \& Miller, 2004).

No photographs were sent as this is not common practice in the UK; instead, the facial disfigurement was defined by a paragraph in the covering letter and a note on the $\mathrm{CV}$, the use of a wheelchair was defined by a statement in the covering letter and on the $\mathrm{CV}$, and the control condition had no additional information. The use of text to convey the facial disfigurement does allow for 
some ambiguity in the mind of the person reviewing the application; the imagination may paint a worse picture than the reality, or alternatively a matterof-fact verbal description may not live up to the visual impact of a photograph. This ambiguity can only be noted as the constraints of conducting a realistic study left no choice. Each covering letter emphasised the relevant skills and substantial experience in similar positions possessed by the applicant before mentioning either the facial disfigurement or the wheelchair.

In the Facial Disfigurement condition a paragraph of the covering letter read "NB: I was born with a rare non-contagious, congenital disorder that has caused distortion of my facial features". In addition, a note at the top of the CV stated: "Please note: I was born with a rare congenital disease which has caused the bones in my jaw and face to fuse and to stop growing in early infancy. The condition has left me with a highly-distinctive, noticeably-different face. I have never let my condition restrict my life and overcoming people's reaction to my distinctive face has led me to develop my confidence and construct highly effective communication skills that have helped me grow as an individual."

In the wheelchair condition a note at the top of the CV stated simply "wheelchair user" and the covering letter stated "Please note I am a wheelchair user and so will require access ramps if I am called to interview." In the control condition there was no special information.

Information about the disfigurement or disability was included in both CV and covering letter to maximise the chance that the information would be noticed by a busy employer or recruitment consultant who might be skimming the 
applications quickly. It should be noted that the inclusion of information defining a disability in a covering letter was previously used by Louvet (2007), Nordstrom et al (1998), and Bell and Klein (2001).

There is some debate about the best point during the recruitment process to disclose a disability or disfigurement. Many argue that it is best to voluntarily disclose at the outset in order to control the impact on the perceiver, to minimise the activation of automatic negative stereotypes, and avoid the appearance of attempting to deceive (e.g. Hebl \& Skorinko, 2005; Roberts \& Macan, 2006; Stone \& Colella, 1996). Riach and Rich (2002) recommend including a paragraph in the application to explain the disability and the government of the UK also advises early disclosure (DirectGov, 2009; see appendix for relevant extracts). In the case of the present study it was necessary to withdraw from the process as soon as any response was received from the employer. Since no interview would take place, the facial disfigurement or mobility impairment was disclosed at the initial application stage.

Three identities were established with common English surnames and each was allocated to one of the three CVs within each job type. Each identity was assigned a postal address, a mobile telephone number, and an email account. The identities were split into two to control for gender differences, the females being allocated the names Emma Williams, Lisa Taylor and Claire Smith, and the males Paul Williams, John Taylor and Daniel Smith, chosen to reflect common popular forenames for the period in which the applicants were reported to have been born. Only female identities were used for the PA position as it was 
predicted that companies receiving three male applications for these positions may regard the applications as suspicious and therefore compromise the experiment's validity.

Design. Each employer received three CVs, one in each of the experimental conditions (Control, Disfigured, or Wheelchair). The three CVs were rotated so that each $\mathrm{CV}$ appeared equally often in each condition, ensuring that variations among the CVs could not systematically bias decisions in favour of any of the three experimental conditions. Riach and Rich (2002) recommend this approach to provide the highest practical level of experimental control. The order in which the applications were sent was also rotated so that the three experimental conditions were sent equally often in first, second and third place. All the CVs sent to an employer represented individuals of the same gender. Male and female CVs were sent to equal numbers of employers, with the exception of the PA position in which all the applicants were female. The dependent variable was the response received from the employer or recruitment agency.

Procedure. Applications were made on a week by week basis by examining the local media for relevant advertisements between April and June 2008. The dates on which the applications were submitted were selected so as to achieve the longest possible time between the three applications for a particular job, with no applications being sent on the closing date or on the day that the advertisement was posted. If a particular advertisement did not state a closing date then the applications were sent out on dates that were at least two working 
days apart. All of the CVs and the covering letters were sent either electronically from the online recruitment website or by email from the personal email accounts established for the fictional identities.

Every working day the email addresses, the telephone voicemail boxes and the postal addresses were checked to see if contact had been made by the potential employers. All information received was recorded and any invitations for interview, call backs or requests for further information were immediately cancelled by the experimenter either by email or telephone in order to minimise inconvenience for the companies concerned. Applicant drop out rates are relatively high at point of call back for interview and so this procedure was not incongruent with real events. Ryan, Sacco, McFarland and Kriska (2000) for example, found that nearly $35 \%$ of applicants to the police force withdrew their application at the first hurdle.

A telephone survey was conducted during September 2008 to investigate awareness of the Disability Discrimination Act 2004. A sample of 39 employers, which represents all those who agreed to respond, were asked a series of 5 questions: 'do you employ any disabled staff', 'are you aware of the DDA (2004)', 'do you offer an accessible working environment', 'do you offer accessible recruitment', and 'are you aware of grants available for adapting a working environment to the needs of a member of staff with a disability'. The experimenter made sure that they were talking to the person responsible for recruitment at the employer's company. The intention was to examine a possible 
relationship between awareness of the DDA (2004) and the help available, and discrimination in recruitment.

Ethical considerations. Correspondence testing methodology imposes upon the employer fictitious applicants which potentially could slow the recruitment process. The justification for this minor act of deception is that this is the only way of measure how employers behave in practice as oppose to measuring their self-reported attitudes. Several safeguards were imposed to protect the anonymity of the companies targeted. A full review of the ethical considerations of this type of methodology is provided by Riach and Rich (2004). Ethical approval for the present study was given by the Ethics Committee of the University of East London.

\section{Results}

No responses were received after the end of July 2008. The overall rate of positive responses was around one in four, and one in three in the control condition, which was realistic given the job market at the time and the observation that we had deliberately targeted job types that were likely to receive large numbers of applications. For comparison, Riach and Rich (2002) reviewed a substantial literature on racial discrimination and reported rates of positive responses ranging between $19 \%$ and $100 \%$, while in a more recent study by Bertrand and Mullainathan (2004) only one in 10 (white applicants) and one in 15 (black applicants) received a callback. 
When your face doesn't fit

Following the advice of Riach and Rich (2002) the participants who rejected all applicants were excluded from the analysis on the grounds that these employers do not contribute any useable data relevant to the question of discrimination. When an employer rejects all applications, nothing can be safely assumed about the reasons behind this response, so it is best treated as a 'nonobservation'. Of the original 144 participants, 68 remained in the analysis.

Analysis of ordinal data

A panel of seven recruitment consultants was consulted (via personal conversation) to devise an appropriate coding scheme for the responses. Following their advice, the responses received for each job application were coded as $1=$ invitation to interview (2\%); 2 = call back to talk to the applicant $(20 \%) ; 3=$ request for further information $(<1 \%) ; 4=$ notice of rejection with the possibility of consideration for future positions (keep on file; $<1 \%$ ); $5=$ notice of rejection (8\%); or $6=$ no reply $(68 \%)$. Thus, there were no missing data. These responses are coded in decreasing favourability of response and so represent ordinal data. Response type $6=$ no reply is best understood as a rejection since many job applications where the decision is not to interview will receive no reply. The possibility that an application may have been lost in transit as an alternative explanation for no reply was considered, but the frequency of this occurrence was expected to have been too low to have made an appreciable difference to the results.

Figure 1 shows the mean response for each job type and experimental condition. On average, responses were more favourable in the Control condition 
than the other two conditions. Discrimination appears to be higher in the administrator / receptionist and graduates sales positions, lower in the PA position, and absent in the IT support analyst position.

This pattern supports the prediction derived from consideration of the impact of aesthetics, that is, increasing discrimination with expected level of customer contact.

\section{Mean Response by Job Type and Experimental Condition}

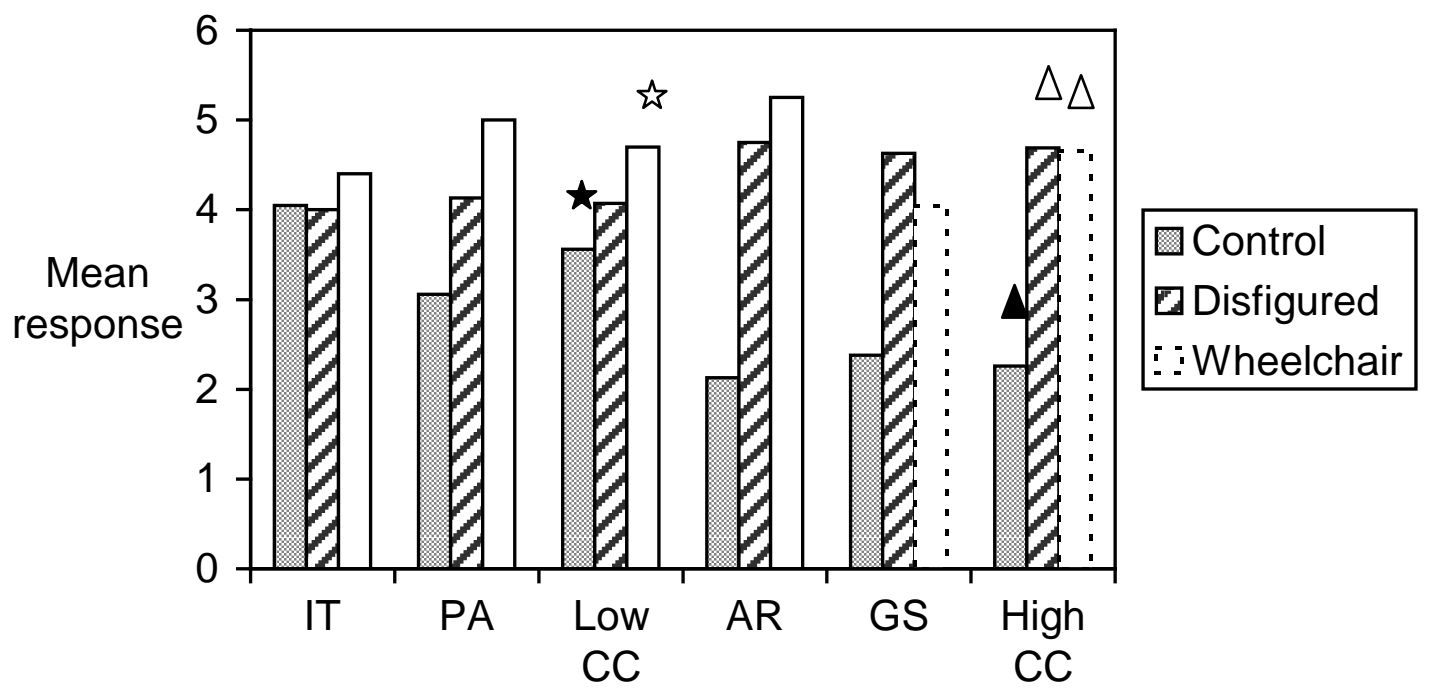

Figure 1: mean favourability of response; a lower mean indicates more favourable response $(1=$ invitation to interview, $2=$ call-back to discuss, $3=$ request for information, $4=$ keep on file, $5=$ reject, $6=$ no reply). $I T=I T$ support analyst, $P A=$ personal assistant,$A R=$ administrator $/$ receptionist,$G S=$ graduate sales. Symbols indicate significant differences. 
In order to improve the power of the analysis and to focus on the aesthetics factor the job types were condensed into two categories of low customer contact (IT support analyst and personal assistant) vs. high customer contact (administrator / receptionist and graduate sales).

Analysis of Variance (Anova) with three factors of experimental condition (Control, Disfigured, and Wheelchair), level of customer contact (low vs. high), and gender (male, female) showed no significant main effect or interaction involving gender, all $p>0.11$, so this factor was excluded from subsequent analysis. Similarly, recruiter type (direct employer vs. recruitment agency) had no significant main effect or interaction, and neither did the sequence in which the applications were sent (coded as control first, disfigured first, or wheelchair first), all $p>0.33$. These factors were excluded from subsequent analysis. Thus the two factors of experimental condition and level of customer contact remained. There was a significant main effect of experimental condition, $F(2,125)=12.03$, $p<0.001$ (using the Greenhouse-Geisser correction) and a significant interaction with level of customer contact, $F(1,125)=3.74, p=0.028$. Simple contrasts revealed that the effect of customer contact differed between the Control and Disfigured conditions, $F(1,66)=6.24, p=0.015$, but not between the Control and Wheelchair conditions, $F(1,66)=1.98, p>0.16$.

Paired-samples t-tests revealed an equivalent level of response favourability between the Control and Disfigured conditions when the degree of customer contact was low, $t(35)=0.80, p=0.43$, but more favourable responses in the Control condition than in the Disfigured condition when the degree of 
customer contact was high, $t(31)=4.59, p<0.001$. In contrast, there was more favourable responding in the Control condition than the Wheelchair condition whether degree of customer contact was low, $t(35)=2.06, p=0.047$ (with no adjustment for multiple tests) or high, $t(31)=4.45, p<0.001$. There was no difference in favourability of responding between the Disfigured and Wheelchair conditions for either low customer contact, $t(35)=1.39, p=0.17$, or high customer contact, $t(31)=0.72, p=0.48$.

This pattern of results shows discrimination against applicants in the facial disfigurement condition only for jobs involving a high level of customer contact, while for applicants in the Wheelchair condition there was discrimination independent of the expected degree of customer contact.

An alternative measure of discrimination was proposed by Riach and Rich (2002). ${ }^{i}$ This measure yielded the same pattern of results, showing a negligible level of discrimination against people with facial disfigurement in jobs requiring little customer contact (9.7\%), but substantial discrimination in jobs requiring a high level of customer contact (58\%). In contrast, discrimination against wheelchair users appears less dependent on the degree of customer contact, being present in both low-customer contact jobs (33\%) and high- customer contact jobs (53\%).

The telephone survey of 39 employers revealed that most (92\%) claimed to be aware of the provisions of the Disability Discrimination Act 2004. Despite this, only $15 \%$ employed any disabled staff, only $18 \%$ claimed to offer an accessible working environment, only $13 \%$ offered accessible recruitment, and 
only $23 \%$ were aware of grants and advice available to an employer taking on a staff member with a disability. These numbers are too unbalanced to perform an Anova with these as additional factors.

\section{Discussion}

Overall, applicants with facial disfigurement or those described as wheelchair users received less favourable responses than control applicants with no such characteristics. Applicants with facial disfigurement were treated less favourably than those in the control condition where the job entailed a high degree of customer contact, that is, the administrator / receptionist and graduate sales roles. They were treated equally favourably than the control condition where the job required less customer contact i.e. the IT support analyst and personal assistant roles. Wheelchair users were treated unfavourably compared to the control condition whether the job entailed little customer contact or much customer contact.

It is interesting to note that the level of discrimination against people with facial disfigurement in the high-customer contact job types (58\% on the Riach and Rich (2002) measure) lies at the upper end of the range of racial discrimination (between 11\% and 50\%) and age discrimination (between 29\% and 60\%) according to the studies reviewed by Riach and Rich (2007). It is also relevant to point out that the difference in the treatment of applicants in the control condition compared to those with facial disfigurement for high-customer contact job types was highly statistically significant. These factors go some way 
towards alleviating concern that the study was too small $(N=68$ analysed responses) to permit the results to be generalised. While the study size should be taken into consideration, and suggests that observed levels of discrimination might vary from setting to setting, it is reasonable to expect recruitment discrimination against people with facial disfigurement to be a general phenomenon. Similarly, the average level of discrimination against wheelchair users is strong (nearly 50\%) which again suggests that discrimination against wheelchair users would be a widespread phenomenon although the exact level might vary from setting to setting.

The finding that recruitment discrimination against people with facial disfigurement was dependent on level of customer contact is consistent with several other studies (Louvet, 2007; Krings \& Olivares, 2007; Tartaglia et al, 2005) and with anecdotal reports that people with facial disfigurements tend to choose low-profile jobs that involve little contact with the general public (e.g. Bradbury, 1997; Hearst \& Middleton, 1997; Rumsey \& Harcourt, 2004).

Higher discrimination in jobs with more customer contact clearly implicates concern about aesthetics as an underlying source of discrimination against people with facial disfigurement. It is also consistent with the aesthetics factor that anticipated level of customer contact had more impact on the recruitment prospects of people with facial disfigurement than those with impaired mobility. In contrast to a wheelchair, the face is the centre of social interaction and very difficult to ignore, hence an aesthetically unappealing face could have considerable impact in a social interaction. 
When your face doesn't fit

Perhaps employers anticipate negative reactions from their customers to an employee with a facial disfigurement, reasoning that cultural values prefer those whose faces are aesthetically appealing. Employers might be tempted to avoid the possibility of invoking such negative reactions by declining to recruit an employee with a facial disfigurement, especially to a sales or receptionist position. The hypothesis that person perception is informed by wider cultural perceptions (e.g. Smith \& Collins, 2009) and that discrimination in individual cases is frequently in accord with widespread social attitudes and tastes (Riach \& Rich, 2002) suggests that an employer would naturally evaluate an applicant against perceived social norms. This would exclude any applicant whose facial appearance was felt to be contrary to prevalent social standards. In simple terms, consider that potential employers might be concerned about two questions: practical considerations around whether the applicant is capable of performing well in the role, and face-preserving considerations about the possible reactions of customers. In a largely customer-facing role, the question of what might customers think is also a practical consideration of whether the individual can perform well in the role.

Similarly, Kurzban and Leary (2001) note that stigmatization occurs not only when an individual is prejudiced, but when it is perceived to be socially acceptable to exclude a member of a certain subgroup from social interaction, i.e. there is a social consensus to avoid people with certain characteristics. If employers believe that it would be considered acceptable by their customers to avoid employing anyone with a facial disfigurement then this would clearly 
contribute to discrimination in recruitment. The possibility of stigma by association suggests that an employer might be reluctant to risk the damage to their image by employing a person with a facial disfigurement or a disability. The Americans with Disabilities Act of 1990 includes items that bar discrimination against people who associate with disabled persons, giving official acknowledgment of the reality of stigma by association and its potential impact in the employment arena. Boyd and Richerson (1992) noted that those who associate with people with facial disfigurement may themselves be ostracised.

It is sometimes argued that market forces would act over time to eliminate discrimination since an employer who practices discrimination increases their costs by not always employing the best person for the job. However, this decline in discrimination need not occur if, as suggested by Riach and Rich (1991), employers are prepared to increase their overall employment costs by declining to recruit an otherwise well-qualified applicant from a less-preferred social group, perceiving that this will improve their standing with customers. It might actually be cost-effective to discriminate in recruitment if customers are indeed prejudiced against dealing with members of less-favoured social groups. This argument suggests that customer reaction lies at the root of discriminatory behaviour and employers merely act as agents for this discrimination. As Akerlof (1980) points out, employers may desire to avoid the costs of violating social customs by employing a person who doesn't physically resemble other employees.

It seems plausible that discrimination against people with mobility impairment may stem from concern about the practical considerations and the 
potential costs of making the necessary accommodations to employ a wheelchair user. This explanation would be consistent with the mere $23 \%$ of employers polled who were aware of the provisions of the Disability Discrimination Act 2004 with regard to grants and advice for employers taking on recruits with disability. It is interesting to note that the overall level of discrimination against wheelchair users in the present study of $43.9 \%$ (on the Riach and Rich (2002) measure) is similar to that seen in two previous studies, Fry (1986) and Graham et al (1990) who reported $37.6 \%$ and $33 \%$ discrimination, respectively.

The absence of any overall difference in the treatment of people with facial disfigurement compared to those with mobility impairment suggests that disfigurement has an impact on employment prospects equivalent to that of being a wheelchair user. This is quite surprising considering that only $13 \%$ of the sample surveyed said they had wheelchair-accessible recruitment, which would be consistent with a high level of discrimination against wheelchair users. This serves to highlight the level of discrimination against people with facial disfigurement.

Previous reports suggest that UK employers have responded favourably to the provisions of the Disability Discrimination Act 2004. For example, Jackson et al (2000) reported a high level of willingness to comply with the legislation in a questionnaire survey of 200 organisations of varying sizes. Bruyere et al (2004) reported in another questionnaire survey of companies contacted via the Chartered Institute of Personnel Development that $47 \%$ said they were actively recruiting people with disabilities and only $20 \%$ reported difficulties in making 
interview or work environments accessible. While it is possible that the companies contacted in these studies were systematically more likely to comply with legislation that the rather more random selection in the present study, there is still some cause for concern about the discrepancy between the pattern observed in the present study and these previous reports. It may be the case that employers tend to express willingness to comply with legislation when directly questioned, but their actual willingness to comply with legislation in a real recruitment setting, where there might be practical and cost implications, is systematically and substantially lower. Concerns for social desirability seem likely to lead to responses in line with legal requirements when directly questioned.

Given the impossibility of enquiring directly of employers and recruitment consultants about their reasons for discriminating against people with facial disfigurements or mobility impairment, considerations of the underlying causes must remain speculative. More research is needed but, inevitably, this is timeconsuming and expensive to conduct.

According to Hebl and Skorinko (2005) applicants with a disability or disfigurement who disclose or acknowledge their condition early are perceived as psychologically healthier because they have come to terms with their condition and can discuss it without becoming emotional. Riach and Rich (2002) recommend including a paragraph in the application to explain the disability and the government of the UK also advises early disclosure (DirectGov, 2009). The results of the present study do not agree with this picture, instead it appears that disclosing a facial disfigurement or mobility impairment at the application stage is 
likely to result in a lower likelihood of securing an interview, except for the case of a person with a facial disfigurement applying for a job involving little customer contact.

Thus, the recommendation to disclose a disability or disfigurement early in the application process is called into question by the results of this study. Given the advice to disclose before the interview (e.g. DirectGov, 2009), it may be that the optimum time for disclosure would be at the stage when the potential employer offers an interview, and cannot gracefully withdraw this offer, but before attending the interview itself. The disclosure would be under the control of the applicant so enabling them to present their experience in a positive light. They would be able to engage the prospective employer in a meaningful conversation and so encourage an effort to overcome instinctive prejudice. Assuming that an interview can be secured, Hearst \& Middleton (1997) explain how social skills training for people with facial disfigurement can be effective in helping them to make a positive impact in the interview.

The situation might be very different for the optimal timing of disclosure of other, non-visible aspects of personal information, e.g. marital status, children, sexual orientation, etc. Since these aspects are non-visible there is no need for them to be disclosed at all. Detailed consideration of these questions is beyond the scope of the present paper but would make a relevant topic for future studies.

It is interesting to speculate about the effect of contact with colleagues who have a disability or disfigurement. A meta-analytic review of inter-group contact theory (Pettigrew \& Tropp, 2006) suggests that contact has a powerful 
effect in reducing prejudice against people with disability. More positive attitudes towards a person with a disability may be observed when the perceiver is in the presence of another person with a disability (e.g. Meyer, Gouvier, Duke \& Advokat, 2001) and employers who already have one disabled employee are more likely to employ another (e.g. Roberts \& Macan, 2006). There is also direct evidence indicating a relationship between interviewer's level of comfort when interacting with persons with disabilities and their evaluations of the interview performance of such individuals (Nordstrom et al, 1998). It seems likely that the media may also have some beneficial role to play, given evidence that exposure to positive exemplars of a discriminated-against minority has the effect of reducing automatic, implicit prejudice against members of that social group (e.g. Dasgupta \& Greenwald, 2001). It was suggested that implicit attitudes may be best altered by tactics that appeal to emotion, so the positive portrayal of popular characters with disability or disfigurement in the media might be one way to elicit a positive emotional response.

Several limitations of the present study should be noted. The positions applied for were all located in London, and although there is no reason to suppose that a different situation would pertain anywhere else in the UK, this limitation should be acknowledged. Four different types of job were sampled but it is possible that different patterns of discrimination would be observed in other types of job. Similarly, different descriptions of the type of facial disfigurement, and its concealability, might have yielded different levels of discrimination, but this is an empirical question that lies beyond the scope of the present paper. The 
When your face doesn't fit

present study examines only potential discrimination in recruitment and not any other form of discrimination that might arise during employment (e.g. training, promotion, or salary discrimination). It is possible that, since no photographs were used, the employers and recruiters might have missed the definition of facial disfigurement or mobility impairment as a result of skimming very quickly through the covering letter. If this occurred then it would have increased the likelihood of a positive response to the job application and thus watered down the observed results. Therefore, this possibility cannot detract from the results.

\section{Conclusion}

The present study complements previous anecdotal observations of the difficulties faced by people with facial disfigurement in finding employment (e.g. Clarke, 1999; Hearst \& Middleton, 1997; Rumsey \& Harcourt, 2004; Walters, 1997) with systematic experimental data. It appears from these results that there is recruitment discrimination against people with facial disfigurement in jobs involving a larger degree of customer contact, suggesting that concerns about aesthetics or potential stigma by association may be important. Discrimination against wheelchair users showed wide variability among the job types but no consistent pattern. 


\section{References}

Akerlof, G.A. (1980). A theory of social custom, of which unemployment may be one consequence. Quarterly Journal of Economics, 94, 749-775.

Bell, B.S. \& Klein, K.J. (2001). Effects of disability, gender and job level on ratings of job applicants. Rehabilitation Psychology, 46, 229-246.

Bertrand,, M. \& Mullainathan, S. (2004). Are Emily and Greg more employable than Lakisha and Jamal? A field experiment on labor market discrimination. American Economic Review, 94, 991-1013.

Blascovich, J., Mendes, W.B., Hunter,S.B., Lickel,B. \& Kowai-Bell,N. (2001). Perceiver threat in social interactions with stigmatized others. Journal of Personality and Social Psychology, 80, 253-267.

Boyd, R. \& Richerson, P.J. (1992). Punishment allows the evolution of cooperation (or anything else) in sizeable groups. Ethology and Sociobiology, 13, 171-195.

Bradbury, E. (1997). Understanding the problems. In R.Lansdown, N.Rumsey, E.Bradbury, T.Carr and J.Partridge (Eds) Visibly Different: Coping with Disfigurement. Oxford: Butterworth-Heinemann.

Bruyere, S.M., Erickson, W.A. \& VanLooy, S. (2004). Comparative study of workplace policy and practices contributing to disability nondiscrimination. Rehabilitation Psychology, 49, 28-38.

Bull, R. \& David,I. (1986). The stigmatizing effect of facial disfigurement: Nigerian and English nurses' and office workers' ratings of normal and scarred faces. Journal of Cross-Cultural Psychology, 17, 99-108.

Cash, T.F. \& Kilcullen, R.N. (1985). The aye of the beholder: Susceptibility to sexism and beautyism in the evaluation of managerial applicants. Journal of Applied Social Psychology, 15, 591-605.

Christman, L.A. \& Slaten, B.L. (1991) Attitudes toward people with disabilities and judgments of employment potential. Perceptual and Motor Skills, 72, 467-475. 
Clarke, A. (1999). Psychosocial aspects of facial disfigurement: problems, management and the role of a lay-led organisation. Psychology, Health \& Medicine, 4, 127-142.

Colella, A., DeNisi, A.S. \& Varma, A. (1998). The impact of ratee's disability on performance judgments and choice as partner: the role of disability - job fit stereotypes and interdependence of rewards. Journal of Applied Psychology, 83, 102-111.

Dasgupta, N. \& Greenwald, A.G. (2001). On the malleability of automatic attitudes: Combating automatic prejudice with images of admired and disliked attitudes. Journal of Personality and Social Psychology, 81, 800-814.

Dembo, T., Leviton, G.L. \& Wright, B.A. (1975). Adjustment to misfortune: A problem of social-psychological rehabilitation. Rehabilitation Psychology, 22, 1100.

Devine, P.G. (1989). Stereotypes and prejudice: Their automatic and controlled components. Journal of Personality and Social Psychology, 56, 5-18.

DirectGov (2009). Declaring a disability. http://www.direct.gov.uk/en/DisabledPeople/Employmentsupport/LookingForWor K/DG 4000219 Retrieved from the world wide web 30 $30^{\text {th }}$ July 2009.

Disability Discrimination Act (2004). http://www.direct.gov.uk/en/DisabledPeople/RightsAndObligations/DisabilityRight S/DG 4001068 Retrieved from the world wide web 30 ${ }^{\text {th }}$ July 2009.

Eagly, A.H., Ashmore, R.D., Makhijani, M.G. \& Longo, L.C. (1991). What is beautiful is good, but .... a meta-analytic review of research into the physical attractiveness stereotype. Psychological Bulletin, 110, 109-128.

Fichten, C.S. \& Amsel, R. (1986). Trait attributions about college students with a physical disability: Circumplex analyses and methodological issues. Journal of Applied Social Psychology, 16, 410-427.

Firth, M., (1981). Racial discrimination in the British labor market. Industrial \& Labor Relations Review, 34, 265-272. 
Firth, M., (1982). Sex discrimination in job opportunities for women. Sex Roles, 8, 891- 901.

Fry, E. (1986). An equal chance for disabled people? A study of discrimination in employment. London: The Spastics Society, Campaigns and Parliamentary Department.

Giancoli, D.I. * Neimeyer, G.J. (1983). Liking preferences toward handicapped persons. Perceptual and Motor Skills, 57, 1005-1006.

Gilmore, D.C., Beehr, T.A. \& Love, K.G. (1986). Effects of applicant sex, applicant physical attractiveness, type rater and type of job on interview decisions. Journal of Occupational Psychology, 59, 103-109.

Gouvier, W.D., Sytsma-Jordan, S. \& Mayville, S. (2003). Patterns of discrimination in hiring job applicants with disabilities: The role of disability type, job complexity, and public contact. Rehabilitation Psychology, 48, 175-181.

Graham, P., Jordan, A. \& Lamb, B. (1990). An equal chance? Or no chance? A study of discrimination against disabled people in the labour market. London: The Spastics Society.

Hearst, D. \& Middleton, J. (1997). Psychological interventions and models of current working practice. In R.Lansdown, N.Rumsey, E.Bradbury, T.Carr and J.Partridge (Eds) Visibly Different: Coping with Disfigurement. Oxford: Butterworth-Heinemann.

Hebl, M.R. \& Skorinko, J.L. (2005). Acknowledging one's physical disability in the interview: does 'when' make a difference? Journal of Applied Social Psychology, 35, 2477-2492.

Heilman, M.E. (1983). Sex bias in work settings: The lack of fit model. Research in Organizational Behavior, 5, 269-298.

Houston, V. \& Bull, R. (1994). Do people avoid sitting next to someone who is facially disfigured? European Journal of Social Psychology, 24, 279-284.

Jackson, C.J., Furnham, A. \& Willen, K. (2000). Employer willingness to comply with the Disability Discrimination Act regarding staff selection in the UK. Journal of Occupational and Organisational Psychology, 73, 119-130. 
Jowell, R. \& Prescott-Clarke, P. (1970). Racial discrimination and white collar workers in Britain. Race, 4, 397-417.

Kelly, A.E., Sedlacek, W.E. \& Scales, W.R. (1994). How college students with and without disabilities perceive themselves and each other. Journal of Counselling and Development, 73, 178-182.

Krings, F. \& Olivares, J. (2007). At the doorstep to employment: Discrimination against immigrants as a function of applicant ethnicity, job type, and raters' prejudice. International Journal of Psychology, 42, 406-417.

Kurzban, R. \& Leary, M.R. (2001). Evolutionary origins of stigmatization: The functions of social exclusion. Psychological Bulletin, 127, 187-208.

Lanigan, S.W. \& Coterrill, J.A. (1989). Psychological disabilities amongst patients with port wine stains. British Journal of Dermatology, 121, 209-215.

Loo, R. (2001). Attitudes of management undergraduates toward persons with disabilities: A need for change. Rehabilitation Psychology, 46, 288-295.

Louvet, E. (2007). Social judgment toward job applicants with disabilities: Perception of personal qualities and competences. Rehabilitation Psychology, 52, 297-303.

Marlowe, C.M., Schneider, S.L. \& Nelson, C.E. (1996). Gender and attractiveness biases in hiring decisions: Are more experienced managers less biased? Journal of Applied Psychology, 81, 11-21.

Meyer, L., Gouvier, W.D., Duke, M. \& Advokat, C. (2001). Influence of social context on reported attitudes of nondisabled students toward students with disabilities. Rehabilitation Counselling Bulletin, 45, 50-52.

Miller, D.A. \& Routh, D.K. (1985). Where women win: Supervisors of school psychologists prefer female job candidates. Professional Psychology: Research and Practice, 16, 42-49.

Newman, J. M. (1978). Discrimination in recruitment: An empirical analysis. Industrial \& Labor Relations Review, 32, 15-23.

Nordstrom, C.R., Huffaker, B.J. \& Williams, K.B. (1998). When physical disabilities are not liabilities: the role of applicant and interviewer characteristics 
on employment interview outcomes. Journal of Applied Social Psychology, 28, 283-306.

Pager, D. \& Quillian, L. (2005). Walking the Talk? What Employers Say versus What They Do. American Sociological Review, 70, 355-380.

Pettigrew, T.F. \& Tropp, L.R. (2006). A meta-analytic test of intergroup contact theory. Journal of Personality and Social Psychology, 90, 751-783.

Pryor, J.B., Reeder, G.D., Yeadon, C. \& Hesson-McInnis, M. (2004). A dual-process model of reactions to perceived stigma. Journal of Personality and Social Psychology, 87, 436-452.

Riach, K. (2007). 'Othering' older worker identity in recruitment. Human Relations, 60, 1701-1726.

Riach, P.A. \& Rich, J. (1991). Testing for racial discrimination in the labour market. Cambridge Journal of Economics, 15, 239-256.

Riach, P.A. \& Rich, J. (2002). Field experiments of discrimination in the marketplace. Economic Journal, 112, 480-518.

Riach, P.A. \& Rich, J. (2004). Fishing for discrimination. Review of Social Economy, 62, 465-486.

Riach, P. A. \& Rich, J. (2004). Deceptive Field Experiments of Discrimination: Are They Ethical? Kyklos, 57, 457-470.

Riach, P.A. \& Rich, J., (2007). An Experimental Investigation of Age discrimination in the English Labor Market: IZA Discussion Paper no. 3029. Bonn, Germany: Institute for the Study of Labor (IZA).

Roberts, L.L. \& Macan, T.H. (2006). Disability disclosure effects on employment interview ratings of applicants with nonvisible disabilities. Rehabilitation Psychology, 51, 239-246.

Rumsey, N., Bull, R. \& Gahagan, D. (1982). The effect of facial disfigurement on the proxemic behaviour of the general public. Journal of Applied Social Psychology, 12, 137-150.

Rumsey, N. \& Harcourt, D. (2004). Body image and disfigurement: Issues and interventions. Body Image, 1, 83-97. 
Ryan, A.M., Sacco, J.M., McFarland, L.A. \& Kriska, S.D. (2000). Applicant self-selection: Correlates of withdrawal from a multiple hurdle process. Journal of Applied Psychology, 85, 163-179.

Smith, E.R. \& Collins, E.C. (2009). Contextualizing person perception: Distributed social cognition. Psychological Review, 116, 343-364.

Stevenage, S. V. \& McKay, Y. (1999). Model applicants: The effect of facial appearance on recruitment decisions. British Journal of Psychology, 90, 221-234

Stone, D.L. \& Colella, A. (1996). A model of factors affecting the treatment of disabled individuals in organisations. Academy of Management Review, 21, 352-401.

Tartaglia, A., McMahon, B.T., West, S.L. \& Belongia, L. (2005). Workplace discrimination and disfigurement: the national EEOC ADA research project. Work, 25, 57-65.

Tsang, H.W.H., Chan, F. \& Chan, C.C.H. (2004). Factors influencing occupational therapy students' attitudes towards people with disabilities: a conjoint analysis. American Journal of Occupational Therapy, 58, 426-434.

Walters, E. (1997). Problems faced by children and families living with visible differences. In R.Lansdown, N.Rumsey, E.Bradbury, T.Carr and J.Partridge (Eds) Visibly Different: Coping with Disfigurement. Oxford: Butterworth-Heinemann.

Weichselbaumer, D. (2003). Sexual orientation discrimination in hiring. Labour Economics, 10, 629-642.

Wilgosh, L.R. \& Skaret, D. (1987). Employer attitudes toward hiring individuals with disabilities: A review of the recent literature. Canadian Journal of Rehabilitation, 1, 89-98.

Wong,D.W., Chan,F., Da Silva Cardosa,E., Lam,C.S. \& Miller,S.M. (2004). Rehabilitation counselling students' attitudes toward people with disabilities in three social contexts: a conjoint analysis. Rehabilitation Counselling Bulletin, 47, 194-204. 
When your face doesn't fit

\section{Appendix 1: Timing of Disclosure}

The government of the UK advises early disclosure of a disability (DirectGov, 2009):

"If you feel that being disabled, or your life experience due to your disability, increases your ability to do the job, mention this on the part of the application that asks why you're suitable for the job. If you don't disclose a disability, it may be harder to explain its positive aspects later on."

And there is further advice on attending interviews:

"If you're shortlisted for an interview, and need practical support ... you should contact the employer to arrange this ... It's a good idea to disclose a disability before an interview ... If you wait until the interview and you have a disability you haven't told the employer about, it may take them by surprise. They may ask irrelevant questions about your disability that you could have answered simply on the application form. The time should be spent explaining why and how you're the right person for the job, not focusing on issues of disability."

' The measure of discrimination proposed by Riach and Rich (2002) was also calculated. This required several indices: $(a)=$ number of employers responding positively to the control applicant and not to the applicant with facial disfigurement; (b) = number of employers responding positively to the applicant with facial disfigurement and not to the control applicant; (c) number of employers responding positively to both applicants. Those employers who rejected, or failed to respond to, both applicants were excluded as non-observations. The measure 
of discrimination is then: $(a-b) /(a+b+c)$ which can be expressed as a percentage by multiplying by 100 .

Binomial tests were performed to compare the number of employers showing a positive response to the Control condition but not the Facial Disfigurement (Wheelchair) condition with the number of employers showing a positive response in the Facial Disfigurement (Wheelchair) condition but not the Control condition (as recommended by Riach and Rich (2002)). A random distribution of favourable responses would give a non-significant test result offering no evidence of discrimination. There was a significant departure from random distribution for the comparison of Control and Disfigured conditions in high customer contact jobs, $p<0.001$, but not in low customer contact jobs, $p=$ 0.69. There was a significant departure from random distribution for the comparison of Control with Wheelchair conditions in both high contact jobs, $p<$ 0.001 , and marginally in low contact jobs, $p=0.093$. 